\title{
The Effectiveness of A Religious Counseling Program According to Albert Ellis' Theory in Treating Psychological Alienation among Syrian Students in Karak Qasabeh's Schools, Jordan
}

Alkafaween Duha, Nashaat Baioumy, Tasnim Binti Mohd Annuar, Roslan Bin Ab Rahman

To Link this Article: http://dx.doi.org/10.6007/IJARBSS/v11-i6/10180

DOI:10.6007/IJARBSS/v11-i6/10180

Received: 12 April 2021, Revised: 15 May 2021, Accepted: 29 May2021

Published Online: 13 June 2021

In-Text Citation: (Duha et al., 2021)

To Cite this Article: Duha, A., Baioumy, N., Annuar, T. B. M., \& Rahman, R. B. A. (2021). The Effectiveness of A Religious Counseling Program According to Albert Ellis' Theory in Treating Psychological Alienation among Syrian Students in Karak Qasabeh's Schools, Jordan. International Journal of Academic Research in Business and Social Sciences, 11(6), 553-569.

Copyright: (C) 2021 The Author(s)

Published by Human Resource Management Academic Research Society (www.hrmars.com)

This article is published under the Creative Commons Attribution (CC BY 4.0) license. Anyone may reproduce, distribute, translate and create derivative works of this article (for both commercial and non-commercial purposes), subject to full attribution to the original publication and authors. The full terms of this license may be seen

at: http://creativecommons.org/licences/by/4.0/legalcode

Vol. 11, No. 6, 2021, Pg. 553 - 569

Full Terms \& Conditions of access and use can be found at http://hrmars.com/index.php/pages/detail/publication-ethics 


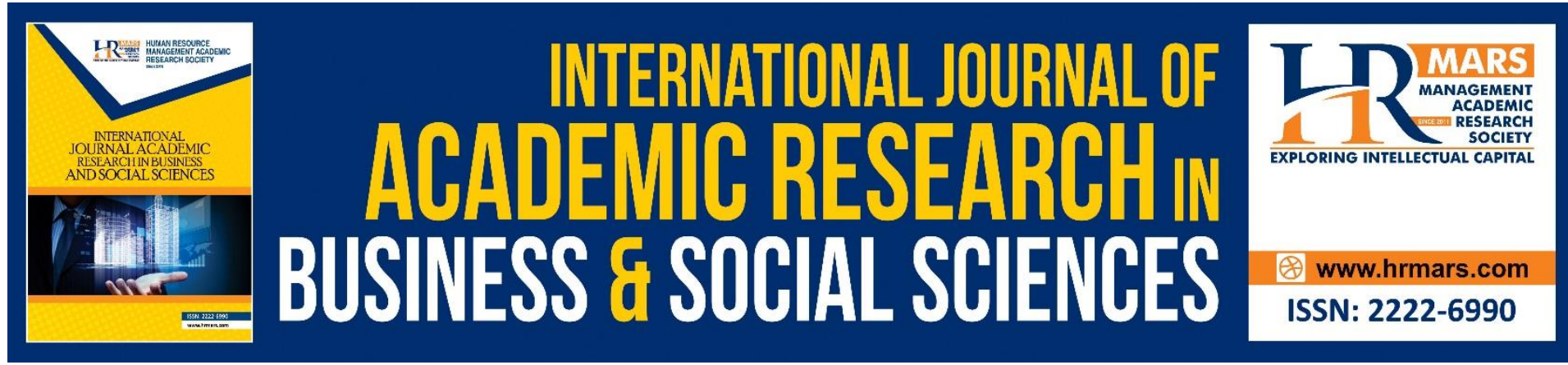

\title{
The Effectiveness of A Religious Counseling Program According to Albert Ellis' Theory in Treating Psychological Alienation among Syrian Students in Karak Qasabeh's Schools, Jordan
}

\author{
Alkafaween Duha, Nashaat Baioumy, Tasnim Binti Mohd \\ Annuar, Roslan Bin Ab Rahman \\ Faculty of Islamic Contemporary Studies, University Sultan Zainal Abidin, Gong Badak \\ Campus, 21300 Kuala Nerus, Terengganu, MALAYSIA \\ Email: nashaatbaioumy@unisza.edu.my
}

\section{Abstract}

The study aimed to identify the effectiveness of a religious counseling program according to the Albert Ellis's theory and its effect in treating psychological alienation among Syrian students in Karak Qasabeh's schools, Jordan. To achieve the objectives of the study, the quasi-experimental approach was used, whereby the study individuals were randomly assigned to two groups: a control group who does not receive the counseling program and the other is experimental group to which the counseling program is applied. Pre and post measurements of the psychological alienation variable were performed for both groups, and follow-up was measured for the experimental group only. The study population and its sample consisted of (60) Syrian students in Karak Qasabeh's schools during the year $2019 / 2020$, and they were divided into two groups, the experimental group of (30) students, and the control group of (30) students. The results of the study showed the effectiveness of a religious counseling program according to the theory of Albert Ellis in treating the psychological alienation of Syrian students in Karak Qasabeh's schools.

Keywords: Religious Counseling Program- Albert Ellis Theory- Psychological Alienation.

\section{Introduction}

The current time is characterized by the fact that it is full of major transformations and changes in the political, economic, social and religious fields; Which caused a gap in the physical and moral developments, and has many disadvantages in developing countries, including the political events in Syria that began in early (2011) and caused radical transformations in all fields of life, where the human rights of the Syrian people were violated and they were forced to leave their homeland to request Safety, so they spread throughout the Arab countries, and Jordan is one of them, and they sought refuge in it to escape the psychological pressures they faced. 
Many psychological effects resulted from this war and its repercussions, which affected the Syrian refugees and reflected on the extent of their stability and compatibility with those around them, and led to their feelings of psychological alienation, sadness, fear and despair, which resulted from an increase in their sense of alienation as a result of the contradiction that they lived in their lives (Abu al-Ghanam, Al-Khaddam \& Naimat, 2016, p.16). So alienation is one of the social and psychological phenomena that encompass all forms of life (political, economic and social). It permeated within the cultures of peoples in a life filled with permanent transformations, which led to the psychological alienation that researchers took care of and studied as psychological phenomena (Yonsei, 2012, p.6) Psychological alienation is predominantly characterized by irrationality and the individual's sense of high potential is one of the causes of anxiety and fear of the future (Zacchaeus and Chukwuorji, 2014. P17 Ifeagwazi). Amara and Bin Daroush (2017, p. 13) explained that psychological alienation is related to the extent to which the individual is separated from his life, himself and others, and that lies in his dissatisfaction with himself, the loss of the meaning of life, his inability to make the right decisions and his inability to achieve them, which leads the individual to a sense of social isolation, And alienation and loneliness.

Syrian students in schools face many psychological consequences resulting from war, conflict and asylum, which are evident in the form of fear, anxiety and constant tension. The individual who lives in an environment full of wars suffers from the feeling that he lives in an estranged place and does not represent him, and is unable to fulfill his requirements and needs, which greatly affects the extent of his adaptation to those around him psychologically, and this will be reflected in the individual's self-confidence, which increases the phenomenon of psychological alienation, which increased significantly over the refugee students, especially the youth, which caused them to have many psychological problems as a result of the change in their lifestyle and livelihood and changed the formation of their personalities (Abbas, 2016, p. 3).

To explain this, the theory of emotional behavioral therapy (Alice) appeared, which explained that individuals are the ones who are able to create behavioral and cognitive problems, and this is the result of the pattern and method of their interpretation of the situations that they live daily, and that thinking, behavior and emotion affect each other, and according to this vision, (Albert Alice confirms that individuals perceive the feeling of psychological alienation in order to build a lot of irrational ideas that are somewhat far from logical thinking, and that is through the psychological disorder that they lived from childhood or through the events that affected their lives, but at the same time they acquire many of these ideas in a way. Self or by repeating negative events and situations that revolve around themselves, and this shows that (Alice) believes that all people do not need to be loved by others despite their importance to them, so whoever feels psychological alienation most of the time stops irrational thinking (David, 2007, p5). So, this theory shows that a person's thinking patterns and beliefs are confined to psychological disorders. Some individuals have a preparation to think contorted in many situations or to defeat themselves or to act strangely (Al-Tamimi, 2016 , p. 80). Psychological alienation from the viewpoint of the theory of emotionalbehavioral therapy is the alienation in which a person faces a decrease and a decline in the degree of social input with barriers that hinder his performance of social work and its results affect mood disorders, anger and loneliness (Turner, 2016, p1). 


\section{Study Problem}

The psychological aspect of the individual has an important role in the formation of his personality and his dealings with others, and its influence appears in childhood and adolescence due to the changes that result from them, which require attention from the family and school, and through the employment of psychological and religious counseling programs, especially for Syrian refugee students (Al-Tashoush \& Al-Asmar, 2017). The Syrian asylum is a group of psychological effects that must be studied, especially the state of feeling of psychological alienation, which leads to indifference, social isolation, feelings of fear, violence, lack of responsibility and bullying (Abu Al-Ghanem et al., 2016, p.16).

Where the researcher noticed that the negative psychological impact of Syrian refugee students in schools as a result of the repercussions of asylum exposes them to falling into psychological disorders and problems such as psychological alienation, which leads to their urgent need for psychological reinforcement, and the use of rational and emotional therapeutic counseling programs that have a role in reducing the level of feeling of psychological alienation, and this What was confirmed by the study of Qabqoub and Saidi (2015) that psychological alienation has a role in social isolation, meaninglessness and impotence, as well as weak religious conviction and introversion, and the religious psychological counseling is one of the most prominent of them through what it does to provide religious counseling programs, which need from the guide and the guide commitment With sincerity and vitality to address psychological problems through worship and contact with God, which confirms the importance of religious programs in schools where Syrian students are present at Karak Qasabeh's schools, Jordan in order to reduce the prevalence of psychological alienation, and accordingly the current study problem answers the main question: What is the effectiveness of a religious counseling program according to Albert Ellis' theory in psychologic alienation among Syrian students in Karak Qasabeh's schools, Jordan?

\section{Study Hypotheses}

1. There is no effectiveness of a religious counseling program according to Albert Ellis' theory in treating psychological alienation among Syrian students in Karak Qasabeh's schools, Jordan.

\section{Study Objectives}

The present study aims to determine the effectiveness of a religious counseling program according to Albert Ellis' theory in treating psychological alienation among Syrian students in Karak Qasabeh's schools, Jordan.

\section{Study Importance}

\section{The Importance of This Study is as Follows}

1. Theoretical importance: The importance of theoretical study lies in the scarcity of studies that dealt with religious counseling program according to Albert Ellis' theory in treating psychological alienation among Syrian students in Karak Qasabeh's schools, Jordan

Within the limits of the researcher's knowledge, this study is one of the few studies in this field in the Arab sector in the Hashemite Kingdom of Jordan, as well as the quantitative addition to the literature related to this field that may generate mental implications in terms of recognizing the feeling of psychological alienation, which helps those interested in education to pay attention to female Syrian students in Karak Qasabeh's schools, Jordan. 
2. Applied importance: The importance of the applied study lies in identifying researchers, decision-makers, and those interested in the religious counseling program to reduce the feeling of psychological alienation among female Syrian students in Karak Qasabeh's schools, Jordan, and provides researchers with a measurement and comparison tool for psychological alienation according to the theory of emotional behavioral therapy / Alice by female Syrian students in Karak Qasabeh's schools, Jordan compared to ordinary people.

\section{Procedural Definitions}

- Religious psychological counseling: It is defined by Al-Hor $(2016$, p.13) as: one of the types of psychological counseling that derives its principles, foundations and methods that it uses from the Qur'an and the Sunnah of the Prophet, and which has great effectiveness and influence in reducing mental disorders, which leads to achieving reassurance, psychological stability and spiritual balance.

- Psychological alienation: Al-Najjar (2016, p.13) defined psychological alienation as: the separation of the individual from oneself, his values, principles, goals and aspirations, his detachment from reality, or alienation from the self, especially since the most important manifestation of alienation is the isolation that causes and leads to this separation.

- It is defined procedurally as: the extent to which female Syrian students in Karak Qasabeh's schools, Jordan feel social isolation, their impotence, their inability to carry out activities of daily life, lack of satisfaction with their lives, and their feeling of pessimism, which is the total degree that Syrian students get on the scale of psychological alienation.

- The theory of emotional-behavioral therapy (ALICE): It is defined as: the human philosophy that is based on its focus on man and not on his actions or his performance, and greatly affects all events of his daily life, and his self, intellectual, emotional and behavioral disorders, and has an effect on the social isolation of the individual and their lack of communication With him with poor performance in everyday social situations (Turner, 2016, p1).

\section{Study Variables}

The independent variable: a religious counseling program according to Albert Ellis' theory. The dependent variable: psychological alienation.

\section{Theoretical Framework \\ Psychological Alienation \\ The Genesis of Psychological Alienation}

The concept of alienation goes back to (Hegel, 1770), who specified that alienation has a double meaning, meaning a positive meaning, which is the serenity of the soul and its orientation towards creativity and a negative meaning that lies in the inability of the self to recognize itself, as Hegel used this concept in two senses indicating the separation of the self from the environment Social (Buroys, 2014, p. 23), but alienation lost its positive meaning and became one-dimensional, and was concerned only with the negative meaning, as it became most of the time dependent on a danger to the freedom of the individual, and this was transferred to the level of philosophical importance (Aref, 2012, p.8).

But the first person to address the concept of alienation on the grounds that it is one of the social phenomena is Karl Marx and as a secular, materialistic concept, as Karl Marx believed that the origins of alienation lie in the work of the expatriate who sees it as the basis for all forms of alienation, whether social, political or ideological within classes Society, and also made a distinction between several aspects of alienation, such as the alienation of the 
individual from his duties, his alienation from himself, his existence, and his alienation from others (Shah, 2015, P48).

The scientist Freud defines psychological alienation as: the alienation of the human being, that is, his alienation from the unconscious, which means the existence of a state of separation between the individual and society and between the individual and the events surrounding him (Bahroun, 2018, P421) and Debla (2015, p.9) defines it as: A state of separation between the individual and himself and himself between him and the other, and his sense of loss and the futility of life and the inability to control everything that is going on around him and that the circumstances are driving him and his lack of belongingness, as he lives in his community among his family in the circle of alienation, in a world devoid of values, which is the result of alienation, subjective, sociopolitical, religious and cultural.

\section{Forms of Psychological Alienation}

Psychological alienation has many forms, including:

1. Self-alienation: It represents the extent of the individual's transition and transformation from a state of self-conflict between the self and external subjective issues; It is a disorder that affects the relationship that aspires to the quality and compatibility between the individual's requirements, needs, desires and inclinations from one angle and his reality from another angle, and this is the style of experience that the individual tells himself as an alien individual, and this person is characterized by dissatisfaction with life, isolation from others, withdrawal and submission ( Kranz, 2013, p. 35).

2. Alienation from others (social alienation): It is the individual's feeling and feeling that there is no interaction between himself and those around him, the absence of affection and love for others, and the absence of social cohesion between them (Al-Karnaz, 2013, p. 35).

3. Cultural alienation: It is represented in a person's distancing from the culture of his society and his rejection of it, in order to possess elements of foreign cultures, especially those related to social life, and prefer them to the Arab culture he has, (Amara and Bin Darwish, 2017, p.30).

\section{Dimensions of Psychological Alienation}

The dimensions of psychological alienation and its components are as follows: Abdullah (2008, p. 15):

1. Impotence: It is the feeling that an individual experiences when he does not have any ability or ability to be influential in the situations and events he is exposed to, and also when he does not have the ability to make decisions that relate to his future and make him feel helpless.

2. The non-purpose: It is the individual's feeling and the feeling that he suffers when he loses his aspiration in his life, and he does not have at that time any visions, aspirations and aspirations for the future.

3. Meaninglessness: It is the individual's sense that he suffers when he feels that there is no value or meaning to his life, and that it is devoid of future goals and aspirations. 
4. Non-normality: Non-normality is represented in the case that Durkheim described it as "anonymous" that afflicts society, and its meaning is the collapse and demolition of society's standards and values, so that the individual reaches a state of rejection of those societal norms and values, and this is due to the absence of the individual's confidence in his community.

5. Rebellion: It is meant to rebel against reality and not to obey and follow it.

6. Social isolation: It is the feeling that an individual experiences when he feels separated from others and his inability to form social bonds with them.

\section{Albert Ellis Theory}

The theory of rational behavioral therapy goes back to Albert Ellis in the fifties of the last century, where his philosophy was that human beings are affected by the problems surrounding them because it adds irrational beliefs to them, and this is because the nature of man makes him believe this through their feelings and actions, which interact with each other, as he acknowledged. Albert Alice on the negative role of an individual's erroneous perception, as he showed that preventing immersion into illogical beliefs can improve the ability of people to direct all their potentials towards self-realization (Najafi and Baranovich, 2014, p); Whereas in the early nineties of the last century (Albert Ellis) changed his treatment method to rational emotional behavioral therapy, believing that this theory is at a high level of understanding, perception and emotion of the goal and behavior in particular, where behavior is a major part of this theory, and his approach is a behavioral approach It is also believed that whatever happens to the individual in their childhood, all his thoughts, feelings, and actions affect his life (Teater, 2016, P2). The goal of the theory of emotional behavioral therapy is to change illogical beliefs with a number of rational beliefs that are flexible and that contribute to helping a person live longer, happier and more comfortable periods (Najafi and Baranovich, 2014, p4).

The theory of emotional-behavioral therapy is defined as: A type of psychological counseling that depends on refuting the client's irrational thoughts and replacing them with more rational ones. It helps him reach mental health and avoid exposure to mental disorders (Abu Dardir, 2010, p.7).

\section{Techniques of Emotional Behavioral Therapy}

Among the most prominent therapeutic techniques in emotional-behavioral therapy, which are concerned with the guide's special needs, are:

1. Cognitive methods, including: refuting irrational thoughts: which help the guide to discover irrational thoughts and replace them with more rational thoughts, and the homework that the therapist provides to the mentor for his self-help, and the change of language, which is considered one of the causes of the individual's affliction with psychological disorders such as the phrases (must, should), And replacing it with other phrases that help them think in different ways and reduce the negative feelings of the guided person (Abd al-Rahman, 2018, p.19).

2. Emotional methods, including: rational emotional imaginations, which are based on motivating the individual to give himself up to think and feel in the way he prefers and to give up disturbing situations and help him replace them with positive and happy attitudes, and the 
role-playing style: which contributes to helping the guide to exclude the irrational thoughts that he possesses and to select There are a number of anxiety-causing situations, and the therapist plays the role of the person causing anxiety, and works to push away the thoughts of the guide, as well as exercises facing and attacking shyness to get rid of irrational thoughts that make him feel shy (Dobson and Mastikhina, 2015, P544).

3. Behavioral methods: including removing the mentor and eliminating sensitivity, modeling, control and self-control, relaxation, and homework (Teater, 2013, P4).

\section{Criticisms of the Theory of Emotional-Behavioral Therapy} The theory of emotional behavioral therapy has a number of criticisms, namely:

1. Focus too much on the mind and ignore the emotions.

2. A direct pattern in which individuals submit to treatment without concern for their beliefs and concepts.

3. This theory does not train the guides on the thinking methods themselves, but rather receive them readily from the mentor.

4. It is not suitable for children, people with special needs or those with severe mental disorders (Keegan and Holas, 2009, P605).

\section{Previous Studies}

Talahemah, Nazih and Hamdi (2019) study aimed to investigate the effectiveness of a cognitive-behavioral counseling program in reducing rebellious behavior, psychological alienation, and developing social skills among adolescents. To achieve the objectives of the study, an intended sample consisting of (30) adolescents from the tenth and eleventh grades of the model school of Yarmouk University was selected based on their scores on the study scales. The counseling program based on cognitive-behavioral therapy with nineteen sessions of one hour each for six weeks; And a control group of (15) adolescents did not receive any counseling program, and the researcher used the rebellion behavior scale, the psychological alienation scale, and the social skills scale. The results of the study showed that there are statistically significant differences on the total score of the psychological alienation scale and on three dimensions of the scale, namely: loss of standards, social isolation, and a feeling of helplessness, in favor of the experimental group.

Alom, Almeshari, Al-Rebh and Abdelbary, Arfaj, Alamoudi (2018) conducted, A study aimed to find out if there is a real effect in isolation of students on their academic achievement, and this study was conducted on a group of students of the Faculty of Medicine at King Faisal University, the study included (79) students, (59) of them males, and (20) Of the females (questionnaire), and the results showed that there is no relationship between expatriation and academic achievement, and that academic achievement is not affected by alienation. Oksüz and Öztürk (2017) conducted a study aimed at finding out students' perceptions of alienation and to find out if there was an effect of the student's gender, grade level, number of siblings, and the place of residence of the student's family on the level of alienation. The study was conducted on (300) university students. The data through the "students' alienation scale" was used to analyze the data and the descriptive approach. The results showed that the level of alienation is affected by the class, the number of brothers, gender and place of residence, which leads to a large difference in the levels of alienation.

The study of Amara and Bin Darwish (2017) aimed to reveal the nature of the relationship between psychological alienation and the academic adaptation of the students of the martyr Hama Lakhdar-Al-Wadi. It also seeks to reveal the differences in the phenomenon of 
psychological alienation in the degree of academic adaptation according to the following variables: gender, academic level, and location Residence, and the current study was determined by the descriptive approach, and the sample was chosen in a stratified random manner from the Valley University, and we relied on two tools to collect data, which are the questionnaire that measures the level of psychological alienation, and a questionnaire that measures the level of academic adjustment among university students, and the results of the research resulted in the existence of a positive correlation between Psychological alienation and academic adjustment, which indicates that the lower the degree of psychological alienation, the greater the degree of academic adjustment among university students, and vice versa.

\section{Commenting on Previous Studies}

Previous studies varied in dealing with psychological alienation among students, in the study of Talahemah, Nazih and Hamdi (2019) that investigated the effectiveness of a cognitivebehavioral counseling program in reducing rebellious behavior and psychological alienation and developing social skills among adolescents, and in the study of Amara and Bin Darwish (2017) that revealed the nature of the relationship Which links psychological alienation with the academic adaptation of university students, while the study of Alom, Almeshari, Al-Rebh and Abdelbary, Arfaj, Alamoudi (2018) examined whether there is a real effect in students' isolation on their academic achievement.

\section{Methodology}

The Limits of The Study

1. Objective boundaries: A religious counseling program according to Albert Ellis' theory and its effect in treating psychological alienation among Syrian students.

2. Spatial boundaries: Karak Qasabeh, Jordan.

3. Temporal boundaries: Syrian students in Karak Qasabeh's schools, Jordan, in the 2019/2020 academic year.

\section{Study Approach}

The current study followed the quasi-experimental approach, which is based on the random assignment of study individuals into two groups: one is a control who does not receive the counseling program, and the other is experimental to which the counseling program is applied.

\section{Study Population}

The study population consisted of Syrian students in Karak Qasabeh's schools during the year $2019 / 2020$.

\section{The Study Sample}

The sample was chosen randomly by Syrian students in Karak Qasabeh's schools, where the study sample consisted of (60) students, and they were divided into two groups, the experimental group, which numbered (30) students, and the control group, which numbered (30) students. 


\section{Study Tools}

Psychological alienation scale: The psychological alienation scale was developed after referring to a set of measures of psychological alienation in Arab and Western studies and by reviewing previous research and studies related to the subject of the study, in order to benefit from them, especially in identifying the areas of the scale and formulating its paragraphs, such as the study of Talahemah Nazih and Hamdi (2019).

\section{Validity of Psychological Alienation Scale}

The validity indicators of the scale were verified in two ways, as follows:

Validity of the Content: The scale was presented to (10) referees from the faculty in Jordanian universities who are specialists in psychological counseling and psychology, to express their observations regarding the validity of the paragraphs to measure what they were measured, and with regard to their formulation and suitability to the environment, and a consensus of (80\%) was adopted There are more than the arbitrators on the validity of the paragraph to be included in the scale, and their observations in terms of deletion and modification will be taken into account.

Validity of Construction: The construct validity of the psychological alienation scale was extracted by applying it to an exploratory sample of Syrian students from outside the study sample. Correlation coefficients were found for each paragraph with the total score of the psychological alienation scale.

\section{The Stability of the Psychological Alienation Scale}

Stability indicators were found by re-testing by applying them to an exploratory sample of Syrian students from outside the study sample with a time interval of two weeks, and (Cronbach's Alpha) coefficients were found for the scale, and tables (2) and (3) illustrate this.

Table (2)

Cronbach's alpha coefficient to measure the reliability of psychological alienation scale for the experimental group

\begin{tabular}{|l|l|l|}
\hline The scale & The Number of paragraphs & Cronbach Alpha \\
\hline psychological alienation & 30 & $89 \%$ \\
\hline
\end{tabular}

Table (2) shows that the Cronbach alpha values of the psychological alienation scale for the experimental group were at $89 \%$, which is a high value suitable for scientific research purposes.

Table (3)

Cronbach's alpha coefficient to measure the reliability of psychological alienation scale for the control group

\begin{tabular}{|l|l|l|}
\hline The scale & The Number of paragraphs & Cronbach Alpha \\
\hline Psychological alienation & 30 & $83 \%$ \\
\hline
\end{tabular}

Table (3) shows that the Cronbach alpha values of the psychological alienation scale for the control group were at $83 \%$, which is a high value suitable for scientific research purposes. 
1. Correcting the psychological alienation scale: the scale consisted in its final form of (30) paragraphs, and the response to each paragraph of the scale was graduated on a scale of quadruple answers (agree with a large degree, agree with a medium degree, agree with a degree weakly, disagree), depending on the applicability of the content of the paragraph On the student, and the scale of answers can be transformed into degrees, the answer takes a large degree of agreement (four degrees), agree with a medium degree (three degrees), agree with a weak degree (two degrees), and disagree (one degree).

2. The counseling program: The researcher has prepared a religious counseling program that is based on a set of foundations and principles in this regard for the process of counseling and psychological counseling, and it is a group of organized counseling methods and techniques that are based on general, religious, philosophical, educational, social and ethical foundations, according to Albert Ellis theory, Such as modeling, role-playing, dialogue, discussion, and reflection, which are offered to Syrian students at Karak Qasabeh's schools, Jordan, whose number is (16) sessions within a maximum period of (6) weeks with two sessions per week, the duration of the session is (60) minute with the aim of reducing their psychological alienation, and to help them overcome crises and psychological pressures.

Validation of the Indicative Program: To verify the validity and suitability of the program, it will be presented to (10) arbitrators from the faculty of Jordanian universities who are specialists in psychological counseling and psychology to judge its suitability in achieving the purpose for which it was built, and any proposals they deem appropriate, and the comments of the arbitrators will be taken into account. 


\section{Discussion of Findings and Recommendations}

First: Discussing the Results of Psychological Alienation

Table (4)

The characteristics of the study sample individuals according to the variables

\begin{tabular}{|c|c|c|c|}
\hline Variable & Categories & Frequency & Percentage \\
\hline \multirow[t]{2}{*}{ Housing type } & a house & 14 & $\% 46.7$ \\
\hline & rent & 16 & $\% 53.3$ \\
\hline \multirow[t]{3}{*}{ place of residence } & Camp & 6 & $\% 20$ \\
\hline & Village & 9 & $\% 30$ \\
\hline & City & 15 & $\% 50$ \\
\hline \multirow{3}{*}{$\begin{array}{l}\text { The student's order } \\
\text { in the family }\end{array}$} & Little & 18 & $\% 60$ \\
\hline & Middle & 8 & \%26.7 \\
\hline & elder & 4 & $\% 13.3$ \\
\hline \multirow{3}{*}{$\begin{array}{l}\text { Economic and social } \\
\text { level }\end{array}$} & High & 5 & $\% 16.7$ \\
\hline & Average & 13 & $\% 43.3$ \\
\hline & Low & 12 & $\% 40$ \\
\hline \multirow[t]{3}{*}{$\begin{array}{l}\text { Parents' educational } \\
\text { level }\end{array}$} & $\begin{array}{l}\text { Secondary and } \\
\text { below }\end{array}$ & 10 & $\% 33.3$ \\
\hline & College & 18 & $\% 60$ \\
\hline & Postgraduate & 2 & $\% 06.7$ \\
\hline \multirow{4}{*}{$\begin{array}{l}\text { With whom does } \\
\text { the student live? }\end{array}$} & the father & 3 & $\% 10$ \\
\hline & the mother & 4 & \%13.3 \\
\hline & Father and Mother & 21 & $\% 70$ \\
\hline & one of the relatives & 2 & $\% 06.7$ \\
\hline
\end{tabular}

It appears from the above table that the "rent" category in the housing type variable obtained (16) samples from the total sample amounting to " 30 " samples, meaning " $53.3 \%$ ", while the "house" category got "14" samples, meaning "46.7\%" As it appears from the above table, the "city" category in the variable of the place of residence obtained (15) samples from the total sample of " 30 " samples, a rate of " $50 \%$ ", while the "camp" category received " 6 " samples. That is, by "20\%", and it appears from the above table that the category of "little" in the order variable in the family had obtained (18) samples from the total sample of "30" samples, meaning "60\%", while the category of "elder" On the "4" sample, meaning "13.3\%", 
and it appears from the above table that the "average" category in the variable of the economic and social level has obtained (13) samples from the total sample of "30" samples, meaning "43.3\%". The "high" category got " 5 " samples, meaning "16.7\%", as it appears from the table above that the "College" category in the parent's educational level variable had obtained (18) samples from the total sample of "30" samples, meaning a percentage. $60 \%$, while the category of "postgraduate" on "2" sample, meaning "06.7\%", and it appears from the table above that the category of "father and mother" in a variable with whom the student lives has obtained (21) samples from the total sample of "30" samples, that is, "70\%" While the "one relative" group got a "2" sample, "06.7\%".

\section{Descriptive Statistical Analysis of Data}

Results related to the hypothesis: According to Albert Ellis, a religious counseling program is not effective and its effect in treating psychological alienation on Syrian students at Karak Qasabeh's schools, Jordan?

To answer this question, the assumption of the normal distribution of responses of the respondents of the study sample to the scale of psychological alienation was first verified, using the Shapiro-Wilk test, and Table (5) shows that.

\section{Table (5)}

Shapiro - Wilk test for the normal distribution of the psychological alienation scale

\begin{tabular}{|r|r|r|r|r|r|r|}
\hline \multicolumn{2}{|l|}{ Control group ( $\mathbf{n = 1 5})$} & \multicolumn{2}{|l|}{ Experimental group (n=15) } & The scale \\
\cline { 1 - 5 } $\begin{array}{l}\text { Statistical } \\
\text { significance }\end{array}$ & $\begin{array}{l}\text { Degrees } \\
\text { of } \\
\text { freedom }\end{array}$ & Statistician & $\begin{array}{l}\text { Statistical } \\
\text { significance }\end{array}$ & $\begin{array}{l}\text { Degrees } \\
\text { of } \\
\text { freedom }\end{array}$ & Statistician & \\
\hline .225 & 15 & .919 & .302 & 15 & .941 & $\begin{array}{l}\text { Psychological } \\
\text { alienation }\end{array}$ \\
\hline
\end{tabular}

It is evident from Table (5) that the value of the significance level is higher than (0.05) for the experimental group for the psychological alienation scale and the overall score. This indicates that the responses of the study individuals follow the normal distribution. Therefore, this test was used.

The arithmetic means, standard deviations, modified averages and standard error of the post-test were extracted for the experimental and control groups on the psychological alienation scale, and Table (6) shows these averages:

Table (6)

The arithmetic means, standard deviations, adjusted means and standard error of the post-test of the experimental and control groups on the psychological alienation scale

\begin{tabular}{|r|l|l|l|l|l|}
\hline \multicolumn{2}{|l|}{ post-test } \\
\hline $\begin{array}{l}\text { Standard } \\
\text { error }\end{array}$ & $\begin{array}{l}\text { Adjusted } \\
\text { means }\end{array}$ & $\begin{array}{l}\text { Standard } \\
\text { deviations }\end{array}$ & $\begin{array}{l}\text { The } \\
\text { arithmetic } \\
\text { means }\end{array}$ & The group & The scale \\
\hline .029 & 2.713 & .219 & 2.711 & Experimental & $\begin{array}{l}\text { Psychological } \\
\text { alienation }\end{array}$ \\
\hline .029 & 3.689 & .088 & 3.691 & Control &
\end{tabular}

It is noted from Table (6) that the modified average of the psychological alienation measure for the performance of the experimental group members reached $(2,713)$, and the adjusted average for the control group members was $(3,689)$ on the post-test. To ensure the 
statistical significance of these differences, the accompanying mono-analysis of variance was performed on the averages of the two groups, and Table (7) shows the results of the analysis.

Table (7)

Analysis of variance associated with the differences between the averages of the experimental and control groups in the post-test of the psychological alienation scale

\begin{tabular}{|l|l|l|l|l|l|l|}
\hline $\begin{array}{l}\text { Eta } \\
\text { square }\end{array}$ & $\begin{array}{l}\text { Statistical } \\
\text { significance }\end{array}$ & F-value & $\begin{array}{l}\text { Average } \\
\text { square }\end{array}$ & $\begin{array}{l}\text { Degrees } \\
\text { of } \\
\text { freedom }\end{array}$ & $\begin{array}{l}\text { Sum of } \\
\text { squares }\end{array}$ & $\begin{array}{l}\text { The source } \\
\text { of the } \\
\text { contrast }\end{array}$ \\
\hline .944 & 0.000 & 117.488 & 15.264 & 1 & 15.264 & $\begin{array}{l}\text { counseling } \\
\text { program }\end{array}$ \\
\hline & & & .086 & 28 & 2.422 & Error \\
\hline & & & & 30 & 149.414 & Total \\
\hline & & & 29 & 9.820 & $\begin{array}{l}\text { Adjusted } \\
\text { total }\end{array}$ \\
\hline
\end{tabular}

It is noticed from Table (7) that there are significant differences at the level of $(0.05)$ between the averages of the experimental and control groups in the post-test on the scale of psychological alienation, and by looking at the averages of Table (6), it is clear that the modified arithmetic mean of the experimental group on the scale of psychological alienation is less than the average of the control group.

The value of $F$ reached (117.488) and the significance level value $(0.000)$, and this difference is due to the effectiveness of the religious counseling program in relieving psychological alienation, and the effect size value was $(0.944)$ for the psychological alienation scale between the control and experimental groups, which is a high value indicating the effectiveness of the counseling program for relieving psychological alienation.

Discussion of the results related to the hypothesis: There is no effectiveness of a religious counseling program according to Albert Ellis' theory and its effect in trating psychological alienation among Syrian students in the schools of the Kasbah of Karak, Jordan.

Examination of the second theory shows the effectiveness of a religious counseling program according to the theory of Albert Ellis in treating psychological alienation among Syrian students at Karak Qasabeh's schools, and this is attributed to the effectiveness of the religious counseling program according to the theory of Albert Ellis in reducing psychological alienation among female students, Where the negative psychological impact of Syrian refugee students in schools increases because of the negative consequences left by asylum on them, and this makes them more likely to suffer from many psychological disorders, such as psychological alienation, which leads them to request psychological support more, and their need for containment significantly, and through the current result it appears that alienation The psychological affliction suffered by the Syrian students in the schools of the Kasbah of Karak, Jordan, was clearly reduced, and their feelings of lack of confidence in themselves and others decreased, and their sense of alienation, neglect, indifference, loss of interest and lack of engagement with their peers, as they acquired coping skills and coexistence, and their level of confidence in themselves and others increased.

In this context, the study of Talahemah, Nazih and Hamdi (2019) found statistically significant differences on the overall score of the psychological alienation scale and on three dimensions of the scale, which are: loss of standards, social isolation, and feeling helpless, in favor of the experimental group, and in the same context the result of the first hypothesis can 
be attributed to The nature of the religious counseling program according to the theory of Albert Ellis, whose methods differed from the cognitive methods, such as the expulsion of irrational thoughts, which allowed them to identify the irrational thoughts within them and replace them with different, more rational ideas. Where it helped them to imagine themselves thinking and feeling the way they wanted, and remembering the unwanted events as they were talking to them in reality, and then helping them replace them with more positive, happy and joyful events and situations. The researcher also noted that the behavioral methods provided an opportunity for them to get rid of sensitivity, and helped them with modeling, self-control, and techniques of self-management, and relaxation, and that giving them homework encouraged them to use exposure and systematic disposal of sensitivity individually.

\section{Second: Recommendations}

\section{Based on the results of the study, the researcher recommends the following:}

1. The necessity to design a religious counseling program to rehabilitate Syrian students at Karak Qasabeh's schools, Jordan with their self-esteem and limit their feelings of psychological alienation.

2. The necessity for schools to adopt training courses aimed at improving and developing the lives of Syrian students at Karak Qasabeh's schools, Jordan.

3. It is imperative that psychologists and social workers provide a deeper understanding of the impact in treating psychological alienation on the mental health of Syrian students at Karak Qasabeh's schools, Jordan.

4. The necessity of conducting more research to know what Syrian students face in Karak Qasabeh's schools, Jordan.

\section{References}

Abbas, D. (2016). Psychological alienation and its relationship to study achievement - a comparative study between secondary school students inmates in accommodation centers and students residing in the Damascus governorate, an unpublished master's thesis, Damascus University, Damascus, Syria.

Abd al-Rahman, W. (2018). The effectiveness of a cognitive behavioral counseling program in improving the level of social skills and reducing isolation behaviors among university students, an unpublished master's thesis, An-Najah National University in Nablus, Palestine.

Abdullah, A. (2008). Psychological alienation and its relationship to mental health among university students - a field study on a sample of university students in Algiers -, an unpublished master's thesis, University of Algiers (Ben Youssef bin Khadda), Algeria.

Abu al-Ghanam, G. H., Al-Khaddam, H., And Naimat, M. (2016). The psychological effects of Syrian refugee students in Jordanian schools according to some variables, Al-Manara Magazine, 22 (2), pp. 15-19.

Abu Dardir, N. (2010). The Effectiveness of a Rational and Emotional Counseling Program in Developing Methods of Facing the Pressures Resulting from Life Events for University Students, Unpublished PhD thesis, Cairo University, Egypt.

Al-Hor, A. (2016). The Effectiveness of an Islamic Psychological Counseling Program to Reduce Symptoms of Psychiatric Depression, Unpublished Master Thesis, Islamic University, Gaza. 
Al-Najjar, H. (2016). Psychological alienation and its relationship to body image and future outlook among the victims of the 2014 aggression on the Gaza Strip, an unpublished master's thesis, Islamic University, Gaza.

Alom, A., Almeshari, A., Abdelbary, E., Arfaj, A., Al-Rebh, Q., and Alamoudi, A. (2018). Effect of Alienation on Academic Achievement Performance of Medical Students of King Faisal University. The Egyptian Journal of Hospital Medicine, 72, (6), 4712-4714

Al-Tamimi, M. (2016) University Advising, 1st floor Amman, Jordan: Debono to teach thinking for publishing and distribution.

Al-Tashoush, R., Al-Asmar, S. (2017). Level of Psychological Symptoms among Syrian Refugee Students in Jordanian Schools, The Second International Conference: Entitled: Refugees in the Middle East, Human Security: The Commitments of the International Community and the Role of Host Societies, Editing - Fawaz Ayoub Al-Momani and Muhammad Fouad Al-Hawamdeh. Irbid: Yarmouk University, 2017. Pp. 215-239.

Amara, R., Bin Darwish, S. (2017). Psychological alienation and its relationship to the academic adaptation of university students - a field study on a sample of students from the University of Shaheed Hama Lakhdar El-Wadi-, an unpublished master's thesis, Shahid Hama Lakhdar University in Wadi, Algeria.

Aref, F. (2012). Parental deprivation in adolescence and its impact on psychological alienation among a sample of adolescent girls in Saudi Arabia (a comparative study), The Arab Journal of Educational and Social Studies, P (1), pp. 7-27.

Bahroun, A. (2018). The Psychical Fragmentation in the Perspectives of Sigmund Freud and Jacques Lacan. Journal of Süleyman Demirel University Institute of Social Sciences. 3:32, p. 421-431.

Buroys, L. (2014). Psychological alienation among Syrian refugees in Algeria (a field study on a sample of Syrian refugees in Skikda and Constantine), an unpublished master's thesis, Al-Arabi Bin Mahidi University - Oum El Bouaghi, Algeria.

David, C. (2007). Cognitive behavioral therapy. Californa: Guilford press.

Debla, K. (2015). The role of the moral family gap in the emergence of psychological alienation in the adolescent "A case study of some adolescents in the city - Biskra - Algeria, ed. (1), Dar Al Jinan for Publishing and Distribution, Amman, Jordan.

Dobson, K., and Mastikhina, L. (2015). Concepts and Methods of Cognitive Therapies. International Encyclopedia of the Social \& Behavioral Sciences, 2nd edition, Volume 4, $p$ 542-547.

Ifeagwazi, C., Chukwuorji, J., and Zacchaeus, E. (2014) Alienation and Psychological Wellbeing: Moderation by Resilience, Alienation and Psychological Wellbeing. DOI 10.1007/s11205-014-0602-1

Karnaz, I. (2013). Psychological experiences in childhood and adolescence and its relationship to psychological alienation among university students in the Gaza Strip, an unpublished master's thesis, Al-Azhar University, Gaza.

Keegan, E., and Holas, P. (2009). Cognitive-Behavioral Therapy: Theory and Practice. file:///C:/Users/user/Downloads/Keegan_holas-CBTlast15_10\%20(1).pdf

Najafi, T., and Baranovich, D. (2014) Theoretical background, therapeutic process, therapeutic relationsh and therapeutic techniques of REBT and CT; and some parallels and dissimilarities between the two approach, International Journal of Education and Research,2(2)p1-12. 
Öksüz, Y., and Öztürk, M. (2017). Relationship between Levels of Student Alienation and Hemsehrilik Attitudes of University Students: A Study on Kyrgyz-Turkish Manas University Students. Universal. Journal of Educational Research 5(7): 1182-1191

Qabqoub, I., \& Saidi, A. (2015). Psychological alienation and substance abuse in a schooled adolescent (a case study), Journal of Educational and Psychological Sciences, 1 (1), pp. 216-237.

Shah, M. (2015). Marx's Concept of Alienation and Its Impacts on Human Life. Al-Hikmat, Volume 35, pp. 43-54.

Talahemah, A., Nazih, M., Hamdi, A. (2019). The effectiveness of a cognitive-behavioral counseling program in reducing rebellious behavior, psychological alienation, and social skills development in adolescents, Journal of Educational Sciences Studies, 46 (1), pp. 271-289.

Teater, B. (2013). Cognitive Behavioural Therapy, file://C:/Users/ONLY\%204/Downloads/CBT.pdf

Turner, M. (2016). Rational Emotive Behavior Therapy (REBT), Irrational and Rational Beliefs, and the Mental Health of Athletes, https://www.ncbi.nlm.nih.gov/pmc/articles/PMC5028385.

Yonsei, K. (2012). Psychological alienation and its relationship to academic adjustment among university students - a field study on a sample of students from Mouloud Mammeri University in Tizi-Ouzou-, an unpublished master's thesis, Mouloud Mammeri TiziOuzou University, Algeria. 